\title{
Lemon Juice Synergistically Preserved with Lactobacilli Ameliorates Inflammation in Shigellosis Mice
}

\author{
M. Khairul Islam ${ }^{1}$, M. Shakhawat Hasan ${ }^{1}$, Md. Abdullah Al Mamun ${ }^{2}$, M. Kudrat-E-Zahan ${ }^{3}$, \\ M. Abdul Alim Al-Bari ${ }^{1, *}$ \\ ${ }^{1}$ Department of Pharmacy, University of Rajshahi, Bangladesh \\ ${ }^{2}$ Department of Genetic Engineering and Biotechnology, Shahjalal University of Science \& Technology, Bangladesh \\ ${ }^{3}$ Department of Chemistry, University of Rajshahi, Bangladesh
}

Copyright (C) 2015 Horizon Research Publishing All rights reserved.

\begin{abstract}
The use of probiotic Lactobacilli has moved from concept to implement in different applications. The study was carried out to establish the synergistic role of co-cultures of Lactobacillus casei, L. delbrueckii, L. plantarum and L. helveticus in lemon juice (LJ) preservation as well as investigate the inflammatory- and toxicity profiles of biopreserved LJ ingested shigellosis mice. Lactobacilli were cultured individually and cocultured with different combinations. Four strain Lactobacilli had significant preservative activity than any other combinations in both free and microencapsulated Lactobacilli. The four microencapsulated bacteria extended shelf-life of the LJ in about two weeks at $4{ }^{\circ} \mathrm{C}$. The free or microencapsulated bacteria were increased acidic $\mathrm{pH}$ into LJ. It was evidently proved that microencapsulated cocultures of different strains remained viable over a long period of time and the probiotically fermented juice were potentially inhibiting the pathogenic growth. For inflammatory acute shigellosis, therapies were divided into six groups: LJ only; LJ containing pathogenic bacteria (PB); LJ containing curd, the source of Lactobacilli; LJ containing curd and PB; LJ containing four Lactobacilli LAB1,3,4,6 and LJ containing chemical preservatives (PR, prophyl paraben and methyl paraben 9:1). Lactobacilli preserved LJ were found to be favorably lower inflammatory haematological profiles such as ESR, WBC count and C-reactive protein (CRP) agglutination in acute shigellosis mice. In addition, biopreserved LJ was safe owing to normal ranges of SGPT, SGOT, SALP and AA levels in shigellosis mice. Prospective studies on mechanisms of the probiotic activities might be enable their new medical applications for food preservation and treatment of inflammatory dysentery patients.
\end{abstract}

Keywords Lactobacilli, Lemon Juice, Microencapsulation, Shigellosis, CRP, SGPT

Short Title: Lactobacilli preserved lemon juice ameliorates inflammation

\section{Introduction}

Biopreservation technology is used microorganismsendogenously or added- and/or their natural antimicrobial products to prolong the shelf life and regulate the growth and proliferation of endogenous pathogenic bacteria in foods. ${ }^{1}$ It involves inoculating probiotic bacteria especially lactic acid bacteria (LAB) particularly Lactobacilli due to their inhibition properties towards undesirable micro-organisms. ${ }^{2}$ Lactobacilli produce a wide range of inhibitory compounds such as organic acids (lactic acid), hydrogen peroxide, diacetyl, bacteriocins and compete with other microorganisms by nutrient depletion. ${ }^{3}$ Lactobacilli are also associated with traditional fermented products and thus have the Generally Recognized as Safe (GRAS) status granted by the US Food and Drug Administration (USFDA). ${ }^{4}$ In addition, the beneficial effects of LAB from a healthy image associated with probiotic properties are suggested to be due to a number of factors including regulation of intestinal microbial homeostasis, maintenance of the gastrointestinal barrier function that prevents pathogens from adhering, interference with the ability of pathogens to colonize, changes in total enzyme activity in the colon contents, changes in the availability of nutrients and finally modulation of local and systemic immune responses. ${ }^{5}$ Development of foods that promote health and well-being is one of the key research priorities of food industry. Modern technologies in food processing and microbiological food safety standards have reduced but not eliminated the likelihood of food related illness and product spoilage in industrialized countries. Food spoilage occurs frequently by the contamination by pathogens, which are frequent cause of food borne diseases. In order to achieve improved food safety against such pathogens, food industry makes use of chemical preservatives or physical treatments (e.g. high temperatures). These preservation techniques have many drawbacks which includes the proven toxicity of the chemical preservatives, the alteration of the organoleptic and nutritional properties of foods, and especially recent 
consumer demands for safe but minimally processed products without additives. ${ }^{6}$ To harmonize consumer demands with the necessary safety standards, traditional means of controlling microbial spoilage and safety hazards in foods are being replaced by combinations of innovative technologies including biological antimicrobial systems. This trend has favored consumption of foods enriched with physiologically active components including probiotic bacteria. ${ }^{7}$ The increasing demand for safe food has increased the interest in replacing chemical additives by natural products, without injuring the host or the environment. Thus, food industry is targeting to the development of more healthy products due to consumer's demands for decrease of chemical preservatives. Thus, functional foods are considered as the most upsurge area of research interest in the recent few years. ${ }^{8}$ Regarding this matter, probiotics when consumed in enough amounts exert their health benefits, are considered to be as functional foods. The functional foods influence beneficially the consumer's health by improving their intestinal microbial balance. ${ }^{5}$ To improve the beneficial effects and quality of functional food products, LJ (Citrus limon) was formulated with Lactobacilli and sugars that enhances valuable ingredients such as ascorbic acid, citric acid acting as antioxidants. ${ }^{9}$ The formulated LJ may be an alternative vehicle for the incorporation of probiotics because they were rich in nutrients and do not contain starter cultures that compete for nutrients with probiotics. ${ }^{10}$ Thus, the food industry can refer to the juice supplemented with probiotics as 'functional foods'. The objective of this study was to formulate the LJ with probiotics, check for the shelf life of probioticated juice and finally toxicological profiles of the juices.

\section{Materials and Methods}

\section{Preparation of $\mathbf{L J}$}

The fruit, lemon (local name kagzi lebu, scientific name Citrus limon) were purchased from the local market. The selected fruits were washed thoroughly with running tap water, rinsed with distilled water and blotted dry. Then good quality lemons were sliced and the seeds were separated manually from the pulp. The juice was then extracted by hand squeezing and straining the above prepared material through double fold muslin cloth. The LJ was deposited in a sterile container and kept at $4{ }^{\circ} \mathrm{C}$ prior to use for further studies.

\section{Bacterial strain and culture conditions}

Probiotic lactic acid bacteria (Lactobacillus casei (LAB1), L. delbrueckii (LAB3), L. plantarum (LAB4) and $L$. helveticus (LAB6)) were identified based on carbohydrate fermentation profiles, catalase activities and other biochemical tests and used in the study. ${ }^{11}$ The Lactobacilli strains were grown individually in MRS broth at $30^{\circ} \mathrm{C}$ using $0.1-1.0 \%$ inoculum and different combination of inoculum cultures of Lactobacilli were activated at $30^{\circ} \mathrm{C}$ for $24 \mathrm{~h}$ in MRS broth medium. ${ }^{12}$ Before inoculation into $\mathrm{LJ}$, the bacterial cells were washed in sterile saline to remove any residual MRS broth medium. Aliquots $(10 \mathrm{ml})$ of $\mathrm{CJ}$ were dispensed into culture tubes with caps and were statically incubated at $30^{\circ} \mathrm{C}$ after inoculation. Viable cell counts as colony forming units (CFU) of the inoculum were determined by the standard plate method with Lactobacilli MRS medium after $72 \mathrm{~h}$ of incubation at $30^{\circ} \mathrm{C}$. For animal model of human disease studies, shigellosis (bacillary dysentery) caused by Shigella flexneri and S. dysenteriae were collected from International Centre for Diarrheal Disease and Research, Bangladesh (ICDDR'B) and cultured with nutrient broth medium.

\section{pH, Buffer and Turbidity Tests}

Freshly extracted CJ (unadjusted $\mathrm{pH}$ was $2.0-2.6$ ) was adjusted to different $\mathrm{pH}$ from 2.0-7.0 with citric acid buffer with the help of a $\mathrm{pH}$ meter. The $\mathrm{pH}$ of the $\mathrm{LJ}$ after and before inoculation of the inoculum was checked and fixed pH 3.5 with citrate buffer (Sigma Chemical Co.). The absorbance of the LJ was measured using UV spectrophotometer at $540 \mathrm{~nm}$ before and after probiotication. The buffered juices were inoculated with each Lactobacilli strain and different combinations as mentioned earlier and their viability was determined for a period of four to six weeks.

\section{Microencapsulation of bacteria}

Lactic acid bacteria (LAB) cultures were microencapsulated for immobilization using a modified method of Ding group. ${ }^{13}$ Briefly, four Lactobacilli strains; pathogenic bacteria, Shigella flexneri and $S$. dysenteriae and curd organisms were cultured statically in MRS broth and nutrient broth medium and mixed separately with an equal volume of a $3 \% \mathrm{w} / \mathrm{v}$ sterile $\left(121^{\circ} \mathrm{C}, 15 \mathrm{~min}\right.$.) sodium alginate solution at $21^{\circ} \mathrm{C}$. The alginate and organism suspension was slowly dispensed using a pipette into a beaker containing $600 \mathrm{ml}$ of vegetable oil and $1 \mathrm{gm}$ of Tween 80. This emulsion was mixed thoroughly at $200 \mathrm{rpm}$, with a magnetic stirrer. A solution of calcium chloride $(0.01 \mathrm{M})$ was gently added aseptically to the side of the beaker until the emulsion was broken. Alginate jellification occurred, entrapping organisms in the form of solid beads of $2 \mathrm{~mm}$ in diameter. After $60 \mathrm{~min}$, the aqueous phase (remaining amount of calcium chloride) was removed from the calcium alginate beads by decantation. Beads were stored at $4^{\circ} \mathrm{C}$ until utilized. ${ }^{14}$ The enumeration of free LAB cells were performed using methods described by Shah group. ${ }^{15}$ In brief, for the enumeration of microencapsulated organisms, the bacteria were released from the capsules by sequestering calcium ions with a citrate buffer at $\mathrm{pH}$ 3.5. Once liberated, the organisms were enumerated using the methods of Shah group. ${ }^{15,16}$ Enumeration of the organisms in LJ was performed on a weekly basis over a period of six weeks, using MRS and nutrient agar and incubation at $30^{\circ} \mathrm{C}$ for $72 \mathrm{~h}$ under anaerobic conditions. 


\section{Shelf Life Study}

To examine effect of cold storage on cell viability in probiotic $\mathrm{LJ}$, the juice $(25 \mathrm{ml})$ was fermented for $72 \mathrm{~h}$ at $30^{\circ} \mathrm{C}$ and then stored at $+4^{\circ} \mathrm{C}$ for up to six weeks. The juice was taken at weekly intervals, and the viability of probiotic cultures in probiotic LJ containing free and encapsulated bacteria were determined and expressed as $\mathrm{CFU} / \mathrm{ml}$ after culturing Lactobacilli bacteria on MRS anaerobically at $30^{\circ} \mathrm{C}$ for two days. ${ }^{14}$ For long time storage, bacterial colonies were collected from the agar plates, grown in broth and stored $\left(-70^{\circ} \mathrm{C}\right)$ in $15 \%$ glycerol.

\section{In vivo infection experiments}

Wild type C57BL/6 (B6) mice (10 weeks old) were purchased from the animal research branch of the ICDDR'B. All mice were maintained under specific pathogen-free conditions in the experimental facility in University of Rajshahi, Bangladesh where they received sterilized food and water ad libitum. All animal experiments described were approved by Institutional Animal Care and Use committees of University of Rajshahi. A mouse model of shigellosis (bacillary dysentery) was performed as previously described. ${ }^{17-20}$ Briefly, a little modification, to study experimental shigellosis, mice had been passed a quarantine period of 5-6 weeks without diarrhea and had stool cultures negative for Shigella species at least three successive occasions within a week of the beginning of the experiment. Pathogenic bacteria (Shigella flexneri and $S$. dysenteriae) were grown in nutrient broth at $37^{\circ} \mathrm{C}$ overnight and reinoculated with $1 \%$ precultured bacteria in fresh media. For bacterial infection, the challenging dose of $5 \times 10^{8} \mathrm{CFU} / \mathrm{ml}$ virulent bacilli nutrient broth suspension was administered to B6 mice through intraperitoneal (IP) route. Control mice receive sterile broth. There was a variable response with different batches of animals, but the infected animals usually developed clinical signs and symptoms of acute shigellosis 48 to 72 hours after IP challenge. Cultures as well as gross and microscopic observations were made periodically on stool samples from both infected and control mouse and were repeated when the animals were sacrificed at various times after challenge. Pathologic scoring of feces indicating inflammatory diarrhea was performed as described elsewhere. ${ }^{21}$ Pathological markers indicating inflammation were based on the following parameters: inflammatory haematological profiles such as ESR, total WBCs count, latex agglutination slide test for qualitative CRP and blood culture for bacteria; biochemical parameters such as SGOT, SGPT, SALP, and AA also investigated.

\section{Statistical analysis}

All fermentation experiments were conducted in triplicate and the results were expressed as mean \pm S.D (standard deviation). Statistical analysis was performed using Student's $t$-test $\left({ }^{*} P<0.05,{ }^{* *} P<0.01,{ }^{* * *} P<0.005\right.$, N.S.: not significant, throughout the paper).

\section{Results and Discussion}

\section{Cultural characterization of lactic acid bacteria}

More than 20 strains of lactic acid bacteria were isolated from different samples of artisan Rajshahi curds and four strains of Lactobacilli were taken for this study. Based on cultural, and biochemical characterizations, sugar fermentation patterns and antimicrobial activities, the bacterial strains were confirmed as genus levels as Lactobacillus casei (LAB1), L. delbrueckii (LAB3), L. plantarum (LAB4) and L. helveticus (LAB6). In order to obtain a universal co-culture medium that would support to grow well and survive of all the four strains, a number of commercially available media such as MRS, Czapek-Dox (acid $\mathrm{pH}$ 5.3), M17, nutrient broth and agar were investigated for cultures. Liquid cultural conditions were established including anaerobic, aerobic using a shaker, and microaerophilic (small bottle with tight lid on shaker to limit oxygen but ensure good mixing of cells). MRS medium was found to support the growth of each of the test strains, and taken absorbance at $600 \mathrm{~nm}$ following overnight cultures, when optimal culture conditions and inoculum size were used (data not shown). Based on these studies, MRS broth medium was selected for future all assays. The co-cultures of Lactobacilli strains displayed tolerance to broad range of $\mathrm{pH}$ Figure 1. However, bacterial growth was better when $\mathrm{pH}$ ranged from 3 to 4 and maximum at $\mathrm{pH} 3.5$. Co-culture growth for $\mathrm{LAB} 1,4$; $\mathrm{LAB} 3,6$ and $\mathrm{LAB} 1,3,4,6$ were relatively constant in $48-72 \mathrm{~h}$ at $30^{\circ} \mathrm{C}$. The physical appearance of fermented LJ before inoculation of LAB were very light green, flavour before inoculation of $\mathrm{LAB}$, pleasant, initial $\mathrm{pHs}$ before inoculation of LAB, 2.0-2.6 and storage temperature $4^{\circ} \mathrm{C}$. However, after inoculation of $\mathrm{LAB}$, physical appearance of LJ was light green, unpleasant flavour at the end of the shelf life, $\mathrm{pH}$ increased up to 7 at $4^{\circ} \mathrm{C}$. There were high similarities in growth of mono-culture for LAB1, LAB3, LAB4 and LAB6, and were relatively constant in $48-72 \mathrm{~h}$ at $30^{\circ} \mathrm{C}$.

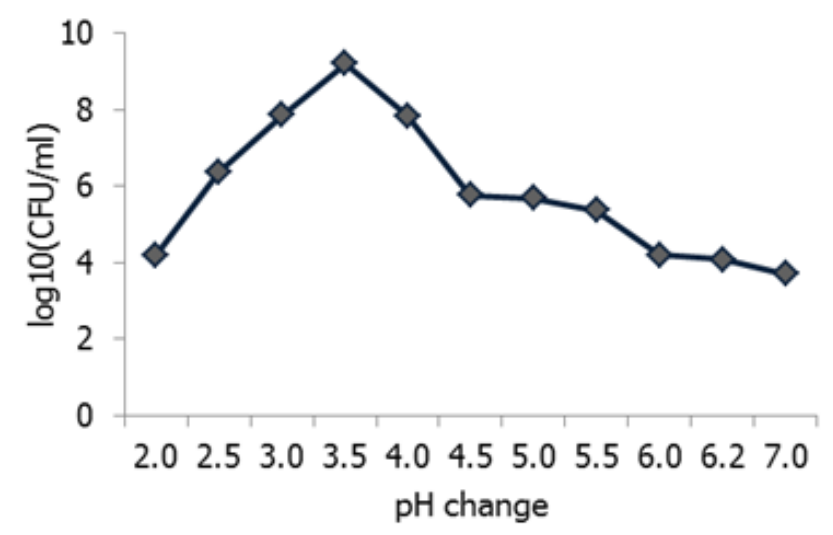

Figure 1. Effect of $\mathrm{pH}$ on colony count during lactic acid fermentation of lemon juice

Survival of Free and Encapsulated Probiotic Bacteria in LJ 
The survival rates of free and microencapsulated Lactobacilli inoculated into LJ were shown in Figure 2A and 2B. Free form of Lactobacilli in cocultures declined rapidly in the $\mathrm{LJ}$ within the four weeks and there were no viable bacteria remaining by the fifth week (Figure $2 \mathrm{~A}$ ). All four strains of probiotic bacteria in monocultures and cocultures showed similar loss of variability. Combined action of LAB 1,3,4,6 had greater viable numbers than all the other monocultures and co-cultures. At the end of 4 weeks, LAB3 had highest viability rate among the monocultures. LAB3 and LAB6 organisms survived in $4^{\circ} \mathrm{C}$ due to its higher tolerance to acids and both organisms were mesophilic facultative heterofermentative. Free multiple probiotic bacteria lost their viability very slowly when compared in single cultured probiotic bacteria in the LJ within the four weeks period and by the fifth week, there were $\geq 10^{4} \mathrm{CFU} / \mathrm{ml}$ viable bacteria (data was not shown). Results indicated as LJ was acidic for probiotic growth multiple co-cultured bacteria were survival rate greater than any single bacteria. The encapsulated probiotic bacteria which were protected from the acidic environment of the LJ did not lose their viability as rapidly as the free probiotic bacteria and $>$ $10^{6} \mathrm{CFU} / \mathrm{mL}$ were still present after six weeks of storage (Figure 2B). The interesting results were found for higher survival rate of free and microencapsulated when multiple probiotic bacteria inoculated into LJ (Figure 2A and 2B). It was important to have a significant number of viable lactic acid bacteria present in the probiotic products for maximum health benefits. ${ }^{22}$ Several factors could affect the cell viability of lactic acid cultures in probiotic food products. Several reports have indicated differences among strains of probiotic bacteria with respect to their survival in acidic environment. ${ }^{13,23}$ Microcapsules may provide a more favorable anaerobic environment for the sensitive probiotic bacteria, as well as a physical barrier from the harsh acidic conditions of the LJ.

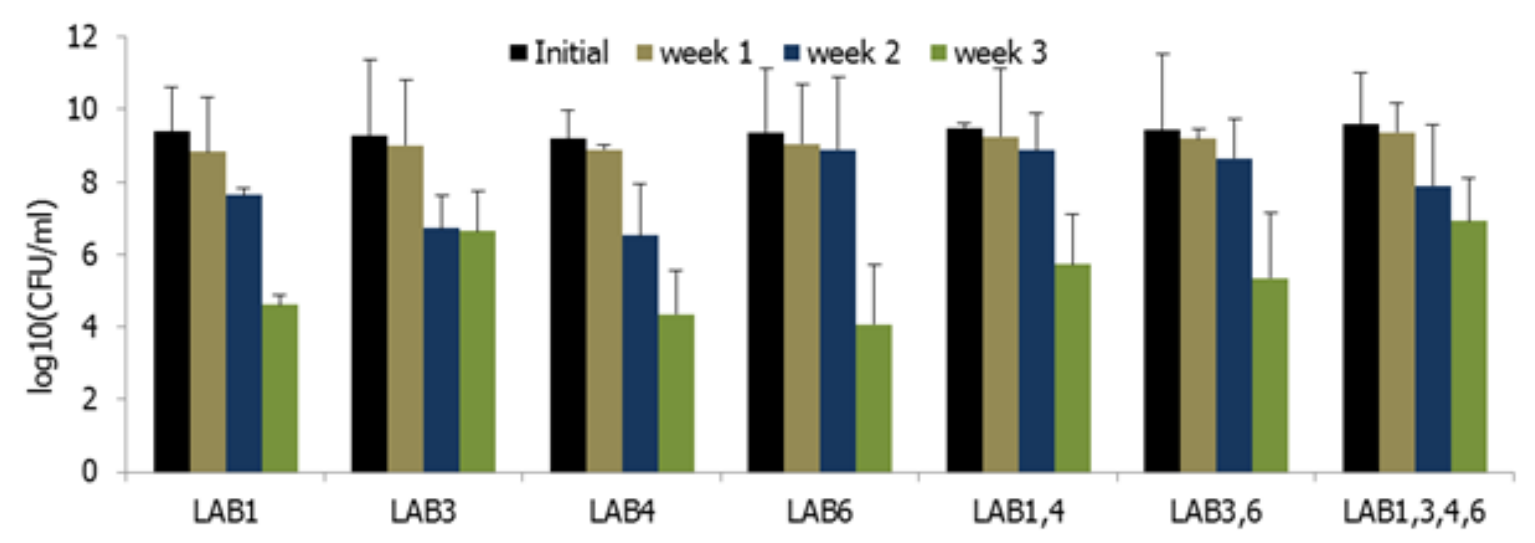

Figure 2A

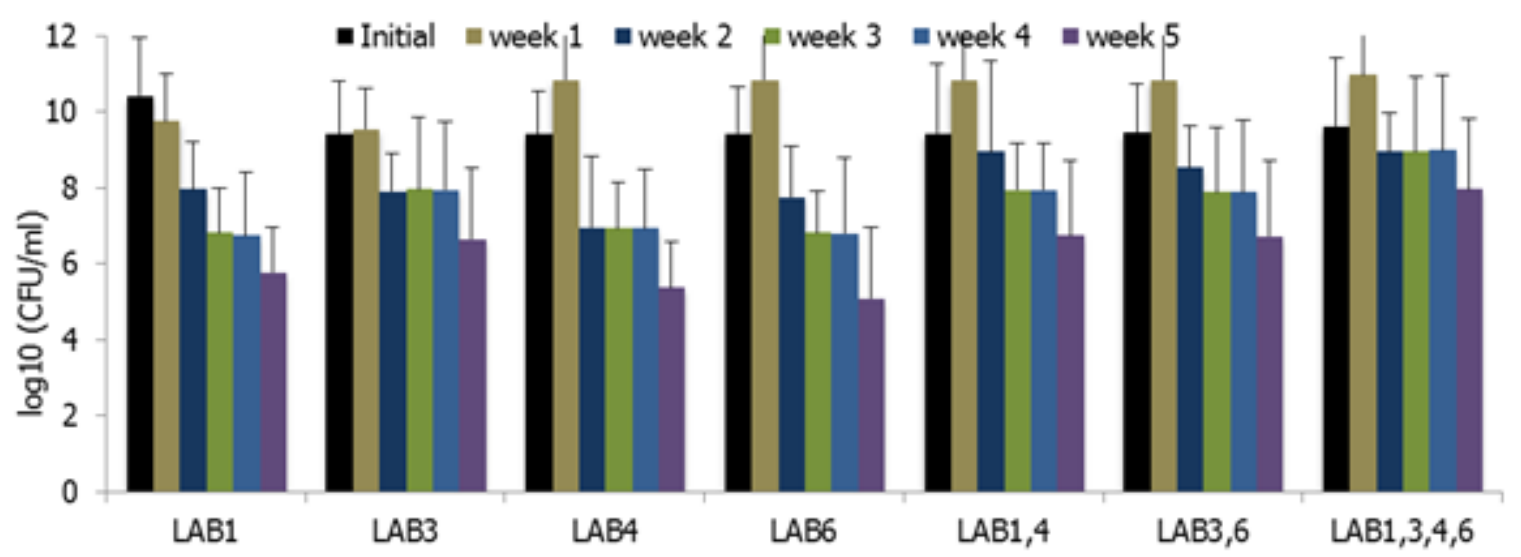

Figure 2B

Figure 2 . A. Viability of free probiotic bacteria preserved lemon juice stored at $4^{\circ} \mathrm{C}$ over a period of 4 weeks. B. Viability of microencapsulated probiotic bacteria preserved lemon juice stored at $4^{\circ} \mathrm{C}$ over a period of 6 weeks 


\section{pH Changes and Buffering action of Probiotic Bacteria on Stability of LJ}

Adjusting the $\mathrm{pH}$ of the $\mathrm{LJ}$ to 3.50 using citrate buffer showed no major difference in survival compared to un-buffered LJ with an initial $\mathrm{pH}$ of 2.0-2.6 (results not shown). The reason for similar results despite the difference in a higher starting $\mathrm{pH}$ could be attributed to the low acid tolerance of the probiotic organisms that were used in this study. Figure $3 \mathrm{~A}$ and3B show the $\mathrm{pH}$ changes in $\mathrm{LJ}$ containing free and microencapsulated probiotic bacteria and their effect on the $\mathrm{pH}$ in $\mathrm{LJ}$ during a storage period of 4-6 weeks. A similar trend in the decline in $\mathrm{pH}$ was seen in both free and microencapsulated LJ with all four probiotic organisms tested. However, the final $\mathrm{pH}$ at the end of the six week storage period of LJ with encapsulated probiotic bacteria was higher than that inoculated with free probiotic bacteria. The average $\mathrm{pH}$ decreased from 3.5 to 2.5 in $\mathrm{LJ}$ containing free probiotic bacteria after four weeks of storage (Figure 3A), whereas the $\mathrm{pH}$ declined to only 2.91 in the juice containing encapsulated probiotics after the storage period (Figure 3B). This result suggested that probiotic bacteria in an immobilized microencapsulated state have a more stable environment. Free probiotic bacteria might have utilized carbohydrates and produced small amounts of organic acids thus lowering the $\mathrm{pH}$ of the product during storage. Many of the free bacteria were not viable at later stages of storage; although the dead probiotic cells could release enzymes for hydrolyzing sugars in the fruit juice, thus lowering the $\mathrm{pH}$. These results demonstrated that microencapsulation of probiotic bacteria would make a more stable product over a longer storage period. Studies had shown that encapsulated probiotic bacteria make more stable functional food products. ${ }^{23,24}$ Figure $3 \mathrm{~A}$ and $3 \mathrm{~B}$ shows the changes in $\mathrm{pH}$ and acidity during $\mathrm{LJ}$ fermentation by LAB1, LAB3, LAB4 and LAB6. Although the LJ had an initial $\mathrm{pH}$ value of 3.5 , the four lactic acid cultures actively fermented the $\mathrm{LJ}$ and lowered the $\mathrm{pH}$ to as low as 2.5. Especially, LAB4 showed a more rapid drop in $\mathrm{pH}$ than the other three lactic acid cultures examined. As shown in Figure 3A and 3B, LAB4 produced significantly more acid during $\mathrm{LJ}$ fermentation than the other three cultures examined.

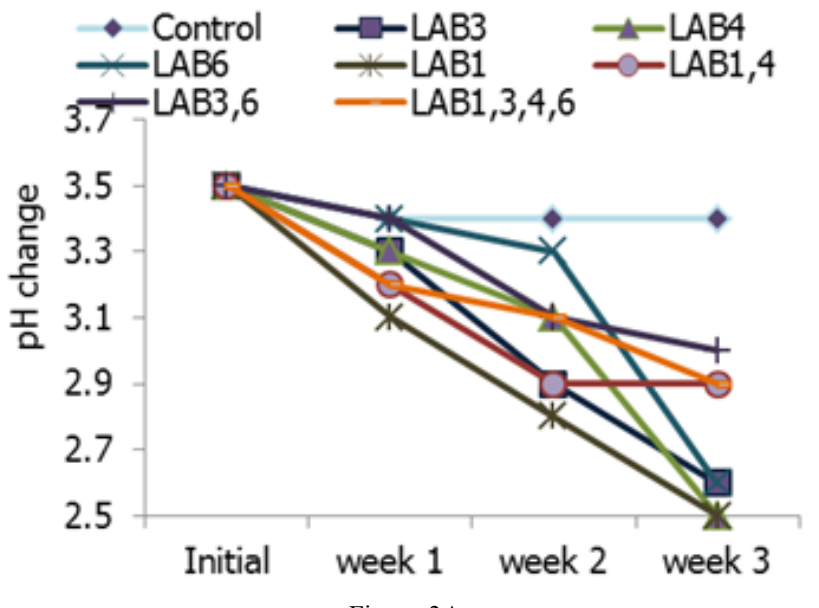

Figure $3 \mathrm{~A}$

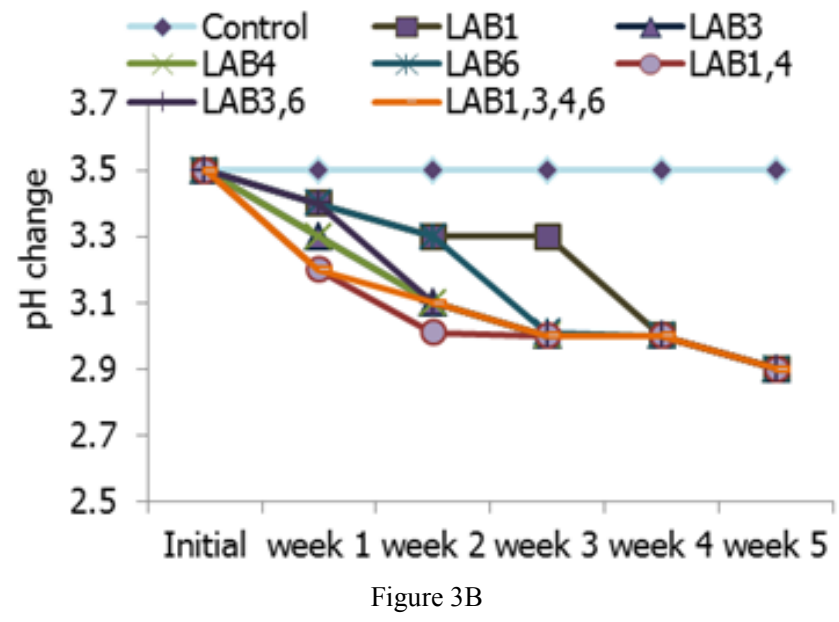

Figure 3. Change in $\mathrm{pH}$ in lemon juice containing (A.) free probiotic bacteria over a period of 4 weeks and (B.) microencapsulated probiotic bacteria preserved lemon juice in a period of 6 weeks

\section{Role of Lactobacilli in LJ Preservation}

The preservative activity of LAB had been observed in some fermented products such as cereals. The lowering the $\mathrm{pH}$ to below 4 through acid production, inhibits the growth of pathogenic microorganisms which can cause food spoilage, food poisoning and disease. ${ }^{25,26}$ By doing this, the shelf life of fermented food was prolonged. This was because the sheer overgrowth of desirable edible bacteria in food out compete the other non-desirable food spoilage bacteria. Thus LAB fermented foods have lactic acid as the main preservative since lactic acid bacterial growth was accompanied by the production of lactic and acetic acids with decrease in $\mathrm{pH}$ and increase in titratable acidity.

In order to investigate the role of lactic acid bacteria in $\mathrm{LJ}$ preservation, we checked $\mathrm{pH}$ change and transmittance of light of LJ only; LJ containing PB; LJ containing curd, the source of Lactobacilli; LJ containing four Lactobacilli LAB1,3,4,6 and LJ containing chemical preservatives (PR, prophyl paraben and methyl paraben 9:1). The Lactobacilli containing $\mathrm{LJ}$ decreased in $\mathrm{pH}$ from 3.5 to 2.9 and transmittance of light was almost equal to $50 \%$ (Figure $4 \mathrm{~A}$ and 4B). After $72 \mathrm{hr}$, pH changes were increased in LJ only, $\mathrm{LJ}$ containing PB; LJ containing curd due to contaminate with other microorganisms. Comparing to Lactobacilli, chemical preservative almost stabled pH of LJ (Figure 4A). After $72 \mathrm{hr}$, turbidity of light was also increased in LJ only, LJ containing PB; LJ containing curd due to grow of some other microorganisms. However, the transmittance of light in LJ containing Lactobacilli and chemical preservative was almost equal (Figure 4B). Probiotic Lactobacilli cultures were commonly used in the dairy industry, and some products produced during lactic acid fermentaion such as lactic acid, diacetyl, and acetaldehyde could be associated with the decrease in $\mathrm{pH}$. In general, the cell viability depends on the strains used; inter action between species present, culture condition, oxygen content, final acidity of the product, and the concentration of lactic acid and acetic acid. The main factors for loss of viability of probiotic organisms have been attributed to the decrease in the $\mathrm{pH}$ of the medium and accumulation of 
organic acid as a result of growth and fermentation. ${ }^{27}$ In this study, most of the four lactic acid bacteria LAB1, 3, 4 and 6 survived in the fermented LJ with high acidity and low $\mathrm{pH}$. A rapid decrease in $\mathrm{pH}$ in the beginning of fermentation was of great importance for the quality of the end product. The rapid increase in acidity minimizes the influence of spoilage bacteria. In the slowly acidified medium, lactic acid fermentation can be suppressed by butyric bacteria activity. The inhibitory action of probiotic bacteria against the pathogens may be due to the accumulation of main primary metabolites such as lactic acid, acetic acids, ethanol and carbon dioxide. Additionally, they also produce secondary metabolites including antimicrobial compounds such as formic acid, benzoic acid, hydrogen peroxide, diacetylacetin, and bacteriocin. The production levels and the proportions among these compounds depend on the strain, medium compounds and physical parameters Probiotics have shown to process inhibitory activities mostly towards Gram positive pathogens and closely selected bacteria due to the bactericidal effect of protease sensitive bacteriocins. ${ }^{28,29}$ The results of our present study agree with Galvez group ${ }^{29}$ who inferred that antimicrobial sub-stances produced by Lactobacillus have a great potential for inhibiting the growth of pathogenic microorganisms.

\section{Lactobacilli reduce inflammation in shigellosis mouse}

In order to study experimental shigellosis, wild type C57BL/6 (B6) (10 weeks old) mice were infected IP with virulent Shigella flexneri and $S$. dysenteriae the challenging dose of $5 \times 10^{8} \mathrm{CFU}$ and found that mice had significantly

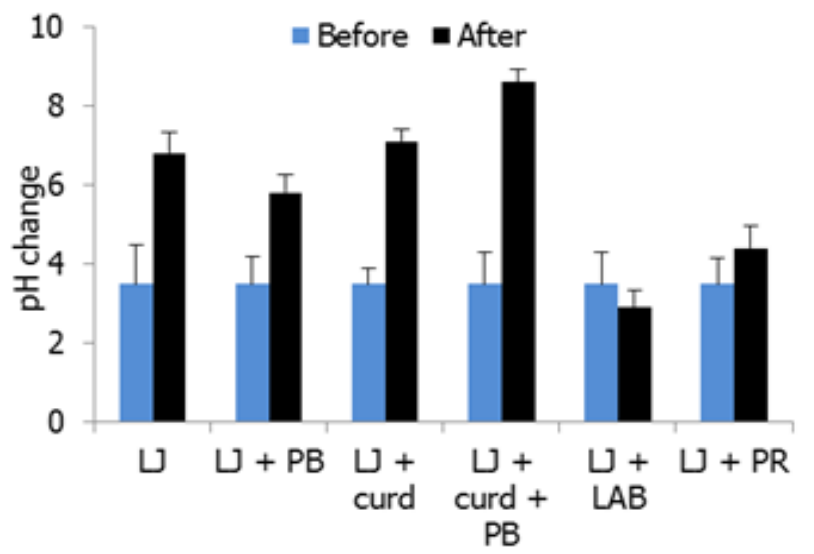

Figure 4A weight loss by 3 days after infection, and all died by day 7 . Consistent with Yang group, B6 mice had severe diarrhea by 2 hours and the symptoms peaked 6 hours and continued until 12 hours as scored by fecal pathology (color and consistency) after intraperitoneal Shigella flexneri and $S$. dysenteriae infection. For inflammatory acute shigellosis, therapies were divided into six groups: LJ only; LJ containing PB; LJ containing curd, the source of Lactobacilli; ); LJ containing curd and PB; LJ containing four Lactobacilli LAB1,3,4,6 and LJ containing PR. Treatment of shigellosis was started at the third day and continued until death occurred and sacrificed all the mice at day 7. Pathological inflammation markers such as ESR, total WBC count, latex agglutination slide test for qualitative CRP and blood culture for bacteria were investigated. For toxicological verifications, SGOT, SGPT, SALP, and AA were also examined. Among the treatment groups, Lactobacilli preserved LJ were found to be favourably lower inflammatory haematological profiles such as ESR, WBC count and CRP agglutination (Figure 5). The results indicated that the Lactobacilli might have a role in controlling inflammatory cytokines. Blood can be infected by pathogenic bacteria or fungi. Blood culture from Figure 6 indicated Lactobacilli predominantly displaced the pathogenic bacteria or fungi. In addition, biopreserved LJ was safe owing to normal ranges of SGPT, SGOT, SALP and AA levels in shigellosis mice (Figure 7). Prospective studies on mechanisms of the probiotic activities may enable their new medical applications for food preservation and treatment of inflammatory dysentery patients.

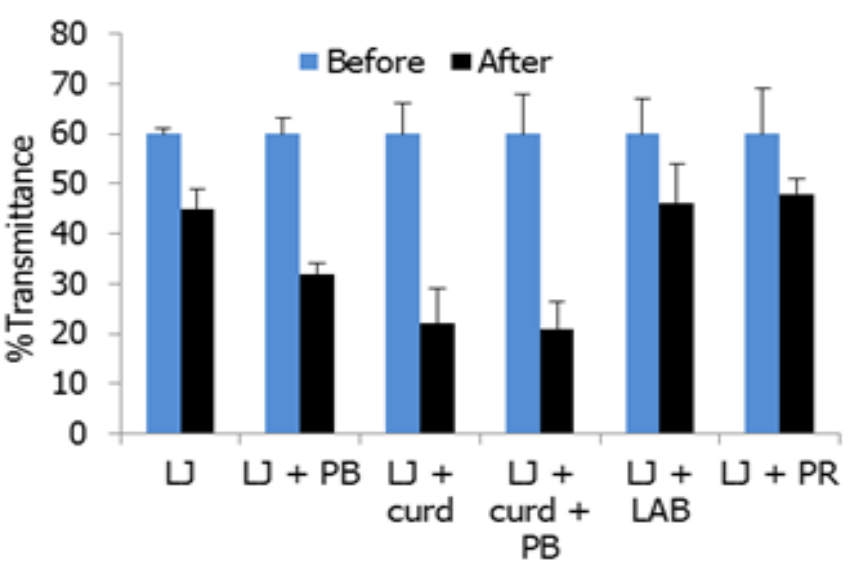

Figure 4B

Figure 4. Effects of (A.) $\mathrm{pH}$ and (B.) transmittance of light before and after 72 hour inoculation of Lactobacilli, curd, pathogenic bacteria and preservative, Where, lemon juice $(\mathrm{LJ})$, pathogenic bacteria $(\mathrm{PB})$, lactic acid bacteria $(\mathrm{LAB})$ and preservative $(\mathrm{PR})$ 


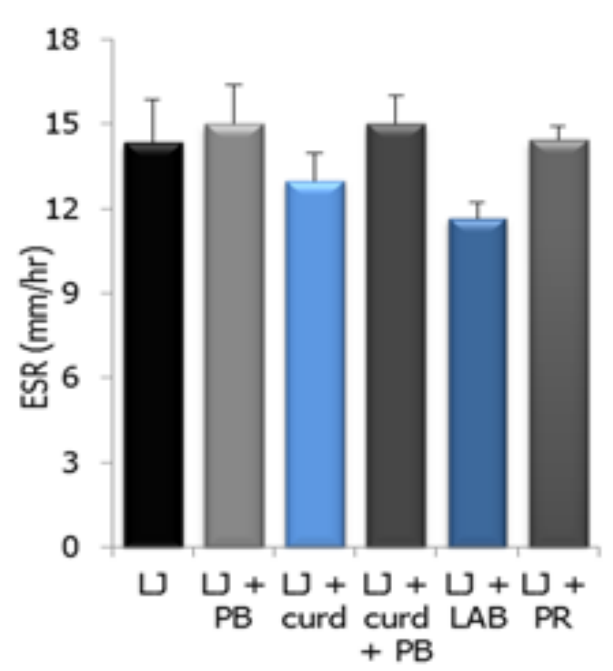

Figure 5A

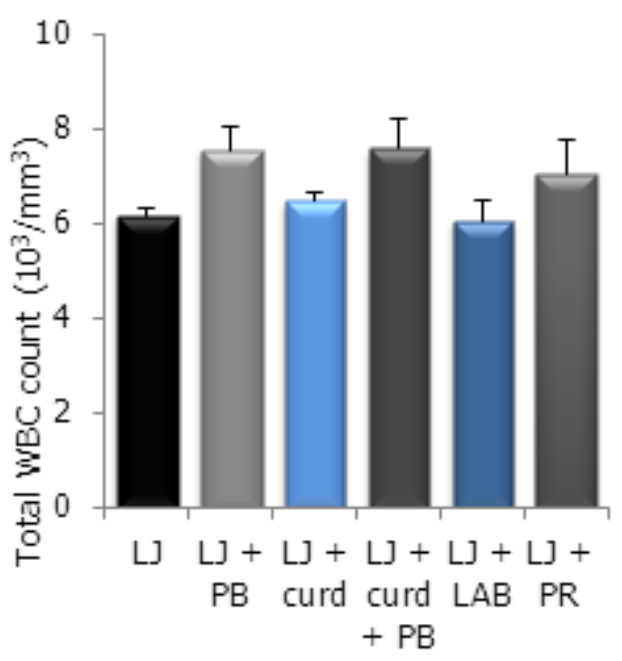

Figure 5B

\begin{tabular}{|c|c|}
\hline Group & indication \\
\hline LJ & ++ \\
\hline LJ + PB & +++++ \\
\hline LJ + curd & ++ \\
\hline LJ + curd + PB & +++ \\
\hline LJ + LAB & + \\
\hline LJ + PR & + \\
\hline
\end{tabular}

Where, lemon juice (LJ), pathogenic bacteria (PB), lactic acid bacteria $(\mathrm{LAB})$ and preservative (PR)

Figure 5C . Qualitative C-Reactive Protein (CRP) level

Figure 5. Inflammatory haematological profiles A. erythrocyte sedimentation rate (ESR), B. total white blood corpuscles (WBC) count, C. qualitative C-reactive protein (CRP) agglutination

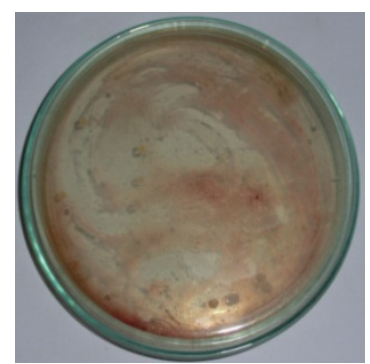

LJ

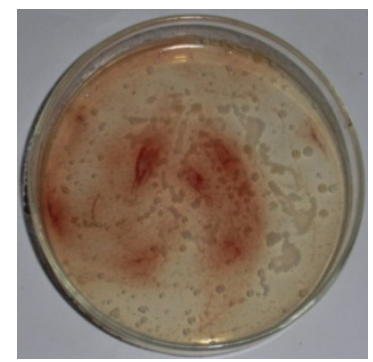

$\mathrm{LJ}+$ curd $+\mathrm{PB}$

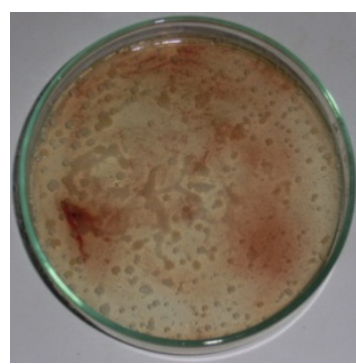

$\mathrm{LJ}+\mathrm{PB}$

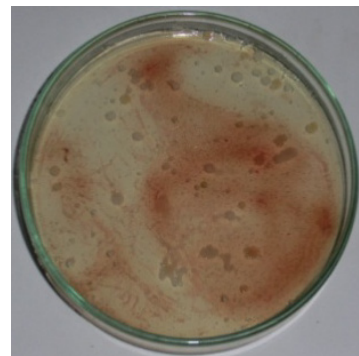

$\mathrm{LJ}+\mathrm{LAB}$

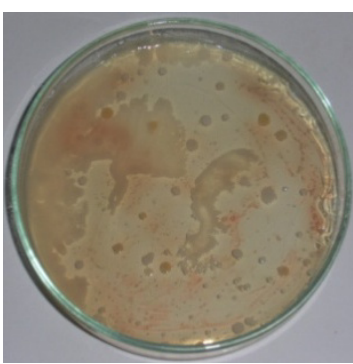

$\mathrm{LJ}+$ curd

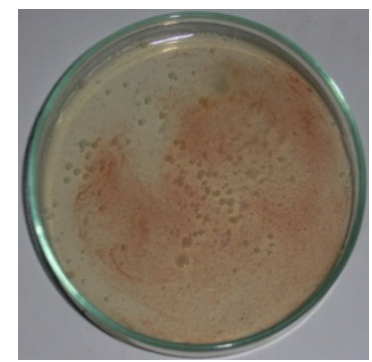

$\mathrm{LJ}+\mathrm{PR}$

Figure 6A 


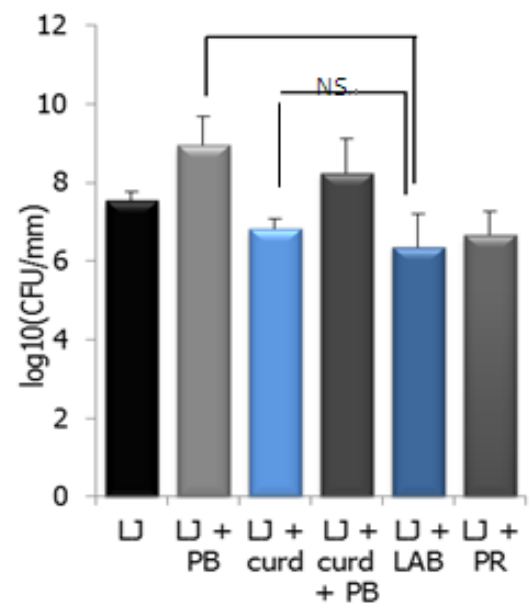

Figure 6B

Figure 6. Blood culture for assessment of colony of bacteria or fungi in blood. A. Blood culture B. Colony count

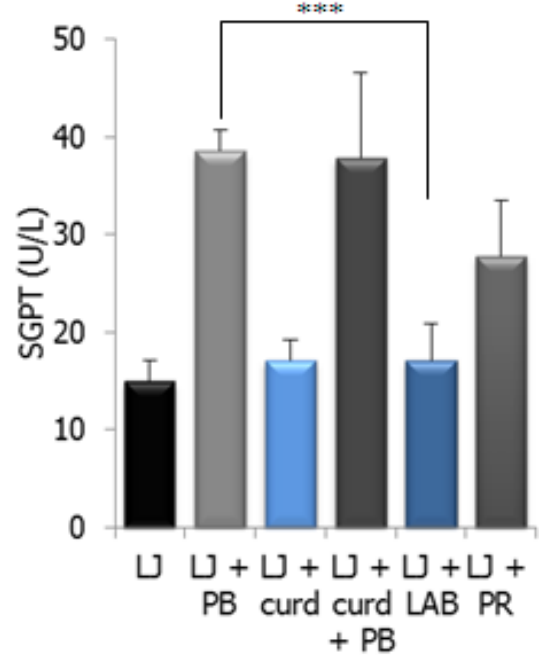

Figure 7A

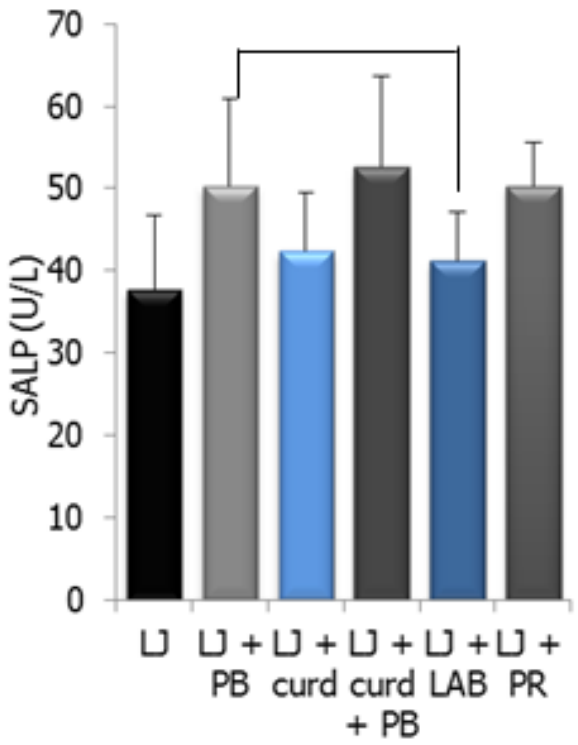

Figure 7C

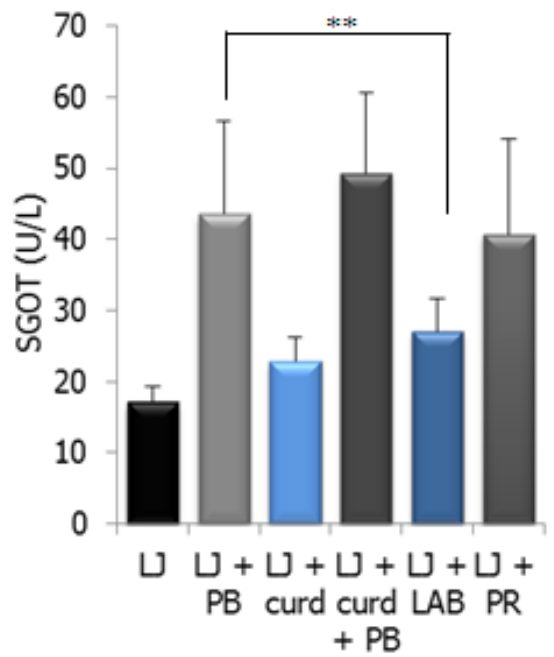

Figure 7B

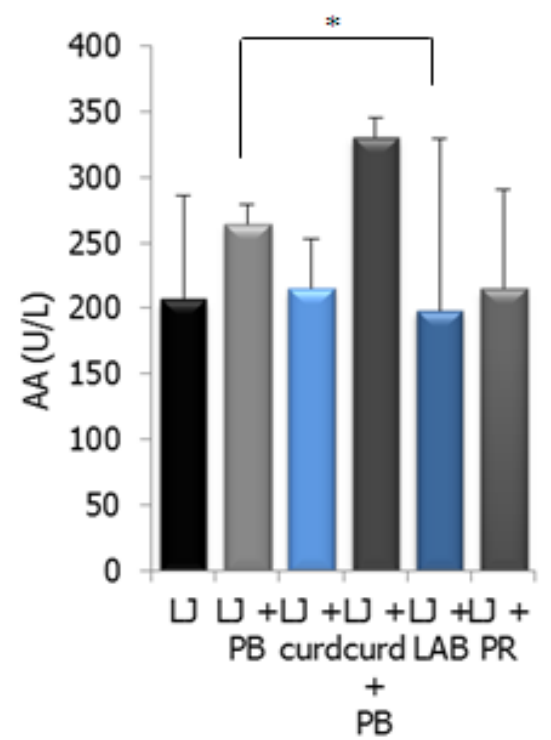

Figure 7D

Figure 7. Toxicological profiles A. serum-glutamate-pyruvate transaminase (SGPT), B. serum-glutamate-oxaloacetate transaminase (SGOT), C. serum alkaline phosphatase (SALP), and D. amylase activity (AA) levels. Where, lemon juice (LJ), pathogenic bacteria (PB), lactic acid bacteria (LAB) and preservative (PR) 
Protection of probiotics especially by microencapsulation in alginate which is non-toxic and being readily available is a method of improving their viability in functional foods. ${ }^{30}$ The primary objective of this study was to determine the survival of probiotic bacteria in LJ during six weeks of storage in order to assess the suitability of a fruit juice as a new alternative functional food. The physical changes to the fruit juice before and after the addition of probiotic organisms were also monitored by assessing changes in $\mathrm{pH}$, and transmittance of light. In this study, probiotics were used to ferment $\mathrm{LJ}$.

Lactic acid bacteria have been added to a variety of dairy-based products such as fermented milks and yogurts for their probiotic human health benefits. ${ }^{31-35}$ In recent years, consumers' demand for non-dairy-based probiotic products has increased. LJ has become popular in recent years due to its health-promoting nutritional components such as ascorbic acids and citric acid. ${ }^{36}$ Ascorbic acids and citric acid act as a powerful antioxidant for preventing tumour growth, enhancing immune response and inhibiting mutagenesis. ${ }^{37}$ However, LJ due to the high acidity, which was unfavourable digestion, formulation to decrease acidity which was turned on the short shelf-life due to enhance microbial growth. ${ }^{37}$ Therefore, controlling the acidity of LJ could be an effective way to extend its shelf-life, and improve its quality and marketability. ${ }^{39,40}$ For the purpose of maintaining the essential composition and quality factors of the juice, the addition of sugars or acids can be permitted to control acidification of the LJ which was endorsed in the individual standard". ${ }^{41}$ In general, the most commonly used methods of controlling acidification of LJ include: adding organic acid, such as citric acid and acetic acid; the use of acid-producing bacteria and blending with acidic fruit juices such as orange, lemon, apple and cranberry juice. ${ }^{42}$ However, a comprehensive study to compare the effects of different acidification methods on LJ quality and stability was not reported.

Home-made LJ was used for all experiments. The fruit juice with no added preservatives and a long shelf life were obtained. Four lactic acid bacteria (LAB 1, 3, 4 and 6) were found capable of rapidly utilizing $\mathrm{LJ}$ for cell synthesis and lactic acid production and co-cultures of the bacteria also reduced the $\mathrm{pH}$ to as low as 2.9 and the viable cell counts (CFU) reached $10^{8} / \mathrm{ml}$ after fermentation of $72 \mathrm{~h}$ at $30^{\circ} \mathrm{C}$. Most of the lactic acid bacteria survived under the low $\mathrm{pH}$ and high acidity conditions during 6 weeks of cold storage at $4{ }^{\circ} \mathrm{C}$. From the results of this study, it was concluded that the fermented $\mathrm{LJ}$ could be used as a raw material for lactic acid fermentation. The probioticated LJ could differ in its antagonistic activities against the pathogens which could be due to the metabolite secreted by the Lactobacilli specially type of organic acids and regulation of acidity. Results obtained in this study would be helpful for developing an appropriate probiotic juice with more health benefits which could be served as a health beverage for vegetarians and consumers who are allergic to dairy products. Although the encapsulation method increases the survival of probiotics in the juice, the effect of probiotic beads on the sensory characteristic and consumers' conception should be analyzed further.

\section{Conclusions}

Fruit juices contain water, sugars, organic acids, vitamins, and trace elements thus providing an ideal environment for spoilage by microorganisms; and most of the juices generally have a lower $\mathrm{pH}(\mathrm{pH}<4.5)$, thus the common feature of their potential spoilage agents is that they must be acid-loving microorganisms. One of the most commonly encountered microbial genera is Lactobacillus. Acid-tolerant bacteria able to grow in juices include lactic acid (Lactobacillus) and acetic acid bacteria (Acetobacter). Most spoilage incidents occurred in spring or summer and spoilage consisted mainly in an off-flavour or -odour production, with or without sediment; sometimes discolouration or cloudiness occurred. Consumer interest towards natural and friendly compounds (essential oils) and/or natural resources like probiotic bacteria caused in the past a renewed attention on alternative natural antimicrobial or anti-inflammatory activities. The use of alternative approaches for juice stabilization appears as a promising trend, due to the increased awareness of consumers towards natural, fresh and nutrient-enriched foods. Juices are usually referred as "vitamin containing foods"; therefore, the use of a processing able to retain vitamins and nutrients or minimize their loss could be advisable. The problem of food spoilage is prevailing especially in the developing countries. ${ }^{43}$ In most of the regions, low temperature is practiced to increase the shelf life of food. In many countries including Bangladesh ambient temperature remain high in most part of the year. In the present scenario of disrupted and expensive supply of electricity provision of low temperature for storage purpose has become out of range for most of the people. In such situations food become more susceptible to bacterial and fungal attack. Antimicrobial agents are available in variety but focus on the legal preservatives and marketing considerations have generated a new trend that use of preservations present are diminishing instead the use of minimal processing and prolonged food shelf life is increasing desired effective means of antimicrobial agents ensuring food safety. ${ }^{44,45}$ Thus, the preservative activity of LAB containing LJ has become in prominent fermented products due to the lowered $\mathrm{pH}$ below 4 that inhibits the growth of pathogenic microorganisms which can cause food spoilage, food poisoning and diseases. By doing this, the shelf life of fermented food, LJ is prolonged.

Food potency losses are serious problems in tropical countries like Bangladesh where ambient of temperature and humidity etc is suitable for microbial growth in conjunction with and food spoilage. Losses in developing countries run high because of poor storage and food handling technologies. Favourable growth conditions for microbes result in deterioration of food in large quantity ranging from $80-85 \%$ damage of crop. ${ }^{43}$ Thus, the LJ 
preserved with LAB may become an important functional food in developing countries like Bangladesh, due to its market reputation and profits extension of shelf life and innate natural tastes.

\section{Abbreviations Used}

Lemon juice (LJ), lactic acid bacteria (LAB), Lactobacillus casei (LAB1), L. delbrueckii (LAB3), L. plantarum (LAB4), L. helveticus (LAB6), pathogenic bacteria (PB), chemical preservatives (PR), C-reactive protein (CRP), colony forming units (CFU), International Centre for Diarrheal Disease and Research, Bangladesh (ICDDR'B), intraperitoneal (IP), erythrocyte sedimentation rate (ESR), white blood corpuscles (WBC), serum-glutamate-oxaloacetate transaminase (SGOT), serum-glutamate-pyruvate transaminase (SGPT), serum alkaline phosphatase (SALP), amylase activity (AA) and not significant (NS).

\section{Acknowledgements}

This work was supported by the research fund of Faculty of Sciences, University of Rajshahi. Authors also thank the laboratory technician Mr. Taimur Rahman for his support and help.

\section{REFERENCES}

[1] Angiolillo, L.; Conte, A.; Zambrini, A.V.; Del Nobile, M.A. Biopreservation of Fior di Latte cheese. J Dairy Sci. 2014, 97, $5345-5355$

[2] El Bassi, L.; Hassouna, M.; Shinzato, N.; Matsui, T. Biopreservation of refrigerated and vacuum-packed Dicentrarchus labrax by lactic acid bacteria. J Food Sci. 2009, 74, M335-339.

[3] Ruiz, F.O.; Gerbaldo, G.; Garcia, M.J.; Giordano, W.; Pascual, L.; Barberis, I.L. Synergistic effect between two bacteriocin-like inhibitory substances produced by Lactobacilli Strains with inhibitory activity for Streptococcus agalactiae. Curr Microbiol. 2012, 64, 349-356.

[4] Badel, S.; Bernardi, T.; Michaud, P. New perspectives for Lactobacilli exopolysaccharides. Biotechnol Adv. 2011; 29, 54-66.

[5] Wells, J. M.; Mercenier, A. Mucosal delivery of therapeutic and prophylactic molecules using lactic acid bacteria. Nat Rev Microbiol. 2008, 6, 349-362.

[6] Nath, S.; Chowdhury, S.; Dora, K.C.; Sarkar, S. Role of biopreservation in improving food safety and storage. Intl $J$ Enginer Res Applic. 2014, 4, 26-32

[7] Yoon, K.Y.; Woodams, E.E.; Hang, Y.D. Probiotication of tomato juice by lactic acid bacteria. $J$ Microbiol. 2004, 42, 315-318.
[8] Kumar, H.; Salminen, S.; Verhagen, H.; Rowland, I.; Heimbach, J.; Bañares, S.; Young, T.; Nomoto, K.; Lalonde, M. Novel probiotics and prebiotics: road to the market. Curr Opin Biotechnol. 2014, 32, 99-103.

[9] Ammar, A.H.; Bouajila, J.; Lebrihi, A.; Mathieu, F.; Romdhane, M.; Zagrouba, F. Chemical composition and in vitro antimicrobial and antioxidant activities of Citrus aurantium 1. flowers essential oil (Neroli oil). Pak J Biol Sci. 2012, 15, 1034-1040.

[10] Abbaszadeh, S.; Gandomi, H.; Misaghi, A.; Bokaei, S.; Noori, $\mathrm{N}$. The effect of alginate and chitosan concentrations on some properties of chitosan-coated alginate beads and survivability of encapsulated Lactobacillus rhamnosus in simulated gastrointestinal conditions and during heat processing. $J \mathrm{Sci}$ Food Agric. 2014, 94, 2210-2216.

[11] Islam, M.K.; Al-Bari, M.A.A.; Khan, A.; Zahan, M.K.; Islam, M.A. Identification and Characterization of Lactobacilli from Rajshahi Traditional Curds. British Microbiol Res J. 2015, 6, 24-31.

[12] Abbas, K.A. "The Synergistic Effects of Probiotic Microorganisms on the Microbial Production of Butyrate In Vitro," McNair Scholars Research J. 2009, 2, 103-110

[13] Ding, W.K.; Shah, N.P. Survival of Free and Microencapsulated Probiotic Bacteria in Orange and Apple Juices. Intl Food Res J. 2008, 15, 219-232.

[14] Mohan, G.; Guhankumar, P.; Kiruththica, V.; Santhiya, N.; Anita, S. Probiotication of fruit juices by Lactobacillus acidophilus. Intl J Adv Biotechnol Res. 2013, 4, 72-77.

[15] Shah, N.P.; Lankaputhra, W.E.V. Improving viability of Lactobacillus acidophilus and Bifidobacterium spp. in yogurt. Intl Dairy J. 1997, 7, 349-56.

[16] Tharmaraj, N.; Shah, N.P. Selective enumeration of Lactobacillus delbrueckii spp. Bulgaricus spp, Streptococcus thermophilus, Lactobacillus acidophilus, bifidobacteria, Lactobacillus casei, Lactobacillus rhamnosus and Propinibacteria. J Dairy Sci. 2003, 86, 2288-2296.

[17] Yang, J.; Lee, S.; Chang, S.; Ko, H.; Ryu, S.; Kweon, M. A mouse model of shigellosis by intraperitoneal infection. $J$ Infect Dis. 2014, 209, 203-215.

[18] Rene, K.; Vidal, P.K.E.; Christine, F.M.; Penlap, N.; Veronique, B.; Magloire, B.S. Shigella dysenteriae Type 1 -induced diarrhea in rats. Jpn J Infect Dis. 2005, 58, 335-337

[19] Shim, D.H.; Suzuki, T.; Chang, S.Y.; Park, S.M.; Sansonetti, P.J.; Sasakawa, C.; Kweon, M.N.; New animal model of shigellosis in the guinea pig: its usefulness for protective efficacy studies. J Immunol. 2007, 178, 2476-2482.

[20] Islam, D.; Ruamsap, N.; Khantapura, P.; Aksomboon, A.; Srijan, A.; Wongstitwilairoong, B.; Bodhidatta, L.; Gettayacamin, M.; Venkatesan, M.M.; Mason, C.J. Evaluation of an intragastric challenge model for Shigella dysenteriae 1 in rhesus monkeys (Macaca mulatta) for the preclinical assessment of Shigella vaccine formulations. APMIS 2014, 122, 463-475.

[21] Kuss SK, Best GT, Etheredge CA, et al. Intestinal microbiota promote enteric virus replication and systemic pathogenesis. Science 2011; 334, 249-52

[22] Ford, A.C.; Quigley, E.M.; Lacy, B.E.; Lembo, A.J.; Saito, Y.A.; Schiller, L.R.; Soffer, E.E.; Spiegel, B.M.; Moayyedi, P. 
Efficacy of Prebiotics, Probiotics, and Synbiotics in Irritable Bowel Syndrome and Chronic Idiopathic Constipation: Systematic Review and Meta-analysis. Am J Gastroenterol. 2014, doi: 10.1038/ajg.2014.202.

[23] Kailasapathy, K. Survival of free and encapsulated probiotic bacteria and ef fect on the sensor y proper ties of yoghur t. Food Sci Technol. 2005, 1, 1-2.

[24] Saarela, M.; Virkajarvi, I.; Alakomi, H-L.; Sigvart-Mattila, P.; Matto, J. Stability and functionality of freeze-dried probiotic Bifidobacterium cells during storage in juice and milk. Intl Dairy J. 2006, 16, 1477-82.

[25] Rasooli, I. Food preservation, a biopreservative approach. Food 2007, 1, 111-136

[26] Doyle, E.M. Microbial food spoilage: Losses and control strategies, A brief review of the literature, Food Research Institute, University of Wisconsin-Madison. 2007.

[27] Aneja, K.R.; Dhiman, R.; Aggarwal, K.N.; Aneja, A.; Emerging preservation techniques for controlling spoilage and pathogenic microorganisms in fruit juices. Intl $J$ Microbiol. 2014, http://dx.doi.org/10.1155/2014/758942

[28] Tonukari, N.J.; Omotor, D.G. Biotechnology and food security in developing countries, Biotechnol. Mol. Biol. Rev. $2010,5,13-23$.

[29] Galvez, A.; Abriouel, H.; López, R.L.; Omar, N.B. Bacteriocin-based strategies for food biopreservation, Int $J$ Food Microbiol. 2007, 120, 51-70.

[30] Abbaszadeh, S.; Gandomi, H.; Misaghi, A.; Bokaei, S.; Noori, $\mathrm{N}$. The effect of alginate and chitosan concentrations on some properties of chitosan-coated alginate beads and survivability of encapsulated Lactobacillus rhamnosus in simulated gastrointestinal conditions and during heat processing. $J \mathrm{Sci}$ Food Agric. 2014, 94, 2210-2216.

[31] Miller, L.E.; Ouwehand, A.C. Probiotic supplementation decreases intestinal transit time: meta-analysis of randomized controlled trials. World J Gastroenterol. 2013, 19, 47184725 .

[32] Lavasani, S.; Dzhambazov, B.; Nouri, M.; Fak, F.; Buske, S.; Molin, G.; Thorlacius, H.; Alefall, J.; Jeppsson, B.; Westrom, B. A novel probiotic mixture exerts a therapeutic effect on experimental autoimmune encephalomyelitis mediated by IL-10 producing regulatory T cells. PLoS One 2010, 5, e9009.

[33] Lee, K.N.; Lee, O.Y. Intestinal microbiota in pathophysiology and management of irritable bowel syndrome. World J Gastroenterol. 2014, 20, 8886-8897.
[34] Mazlyn, M.M.; Nagarajah, L.H.; Fatimah, A.; Norimah, A.K.; Goh, K.L. Effects of a probiotic fermented milk on functional constipation: a randomized, double-blind, placebo-controlled study. J Gastroenterol Hepatol. 2013, 28, 1141-1147.

[35] Papastergiou, V.; Georgopoulos, S.D.; Karatapanis, S. Treatment of Helicobacter pylori infection: Meeting the challenge of antimicrobial resistance. World $J$ Gastroenterol. 2014, 20, 9898-9911.

[36] Dyer, J.; Cleary, L.; Ragsdale-Lowe, M.; McNeill, S.; Osland, C. The use of aromasticks at a cancer centre: A retrospective audit. Complement Ther Clin Pract. 2014, 20, 203-206.

[37] Rossi, T.; Gallo, C.; Bassani, B.; Canali, S.; Albini, A.; Bruno, A. Drink your prevention: beverages with cancer preventive phytochemicals. Pol Arch Med Wewn. 2014, pii: AOP 14094.

[38] Marles-Wright, J.; Lewis, R. Stress response of bacteria. Curr Opin Struct Biol. 2007, 7, 755-760.

[39] Bisen, A.; Pandey, S.K.; Patel, N. Effect of skin coatings on prolonging shelf life of kagzi lime fruits (Citrus aurantifolia Swingle). J Food Sci Technol. 2012, 49, 753-759.

[40] Bevilacqua, A.; Campaniello, D.; Corbo, M.R.; Maddalena, L.; Sinigaglia, M. Suitability of Bifidobacterium spp. and Lactobacillus plantarum as probiotics intended for fruit juices containing citrus extracts. J Food Sci. 2013, 78, 1764-1771.

[41] FAO. Fruit Juices and Related Products. Codex Alimentarius. Volume 6; 1992.

[42] Aprile, A.; Federici, C.; Close, T.J.; De Bellis, L.; Cattivelli, L.; Roose, M.L. Expression of the H+-ATPase AHA10 proton pump is associated with citric acid accumulation in lemon juice sac cells. Funct Integr Genomics 2011, 11, 551-63.

[43] Jabeen, F.; Qazi, J.I. Potential of Bacterial Chitinases and Exopolysaccharides for Enhancing Shelf Life of Food Commodities at Varying Conditions. Intl Res J Environ Sci. 2014, 3, 87-93.

[44] Fuglsang, C.C.; Johansen, C.C., Christgau, S.S.; Adler-Nissen, J. Antimicrobial enzymes: Applications and future potential in the food industry. Trend Food Sci Technol. 1995, 6, 390-396.

[45] Pérez-Pérez, C.; Regalado-González, C.; Rodríguez-Rodríguez, C.A.; Barbosa-Rodríguez, J.R.; Villaseñor-Ortega, F. Incorporation of antimicrobial agents in foodpackaging films and coatings Adv Agri Food Biotechnol. 2006, 37, 193-216. 